\title{
Field Applicability of Decentralized Water Treatment Package System for Small-Scale Water Supply Facility
}

\author{
Ju-Suk An, Young Kyu Park, Ji Young Park, Woosik Jung, and Hyun Je Oh
}

\begin{abstract}
For application in small-scale water facilities, important boundary conditions for decentralized systems include low costs, low maintenance, sustainability. Although some low-cost systems are available, their application is limited by time-consuming daily operation and maintenance. On the other hand, membrane systems are attractive since they provide an absolute barrier for organic compounds and remove turbidity. Accordingly, we developed the membrane based water treatment package system for small- scale water supply facilities, and its applicability was examined. The decentralized water treatment package system consisted of DMF, UF, and UV unit. Each unit combination was made to ensure the processing capacity of $100 \mathrm{~m}^{3}$ per day. In addition, a decentralized water treatment package system was manufactured using 10ft containers compliant with IOS standards due to limitation of grounds at small-scale water supply facility. In case of small-town in Korea, underground water is mainly used as raw water. Therefore, this package system was installed and operated at the upper region of the ANDONG in Korea. Four items including temperature, $\mathrm{pH}$, conductivity, turbidity were monitored to analyze underground water quality. In addition, the water treated by the system was analyzed to identify whether it satisfies drinking water quality standards. After the examination of applicability, on the basis of water usage per capita per day, the system was able to produce enough water for 300 people. During the operation, the produced water satisfied all 48 items of drinking water quality standards. Thus it is surmised that the system could be used for small-scale water supply facilities.
\end{abstract}

Index Terms-Decentralized water treatment system, field application, water treatment package system.

\section{INTRODUCTION}

The valley water and underground water used as the source of water intake by many regional waterworks have become polluted because of continued development of rural areas. Moreover, the soil pollution by excessive use of pesticides and fertilizers as well as the pollutants generated non-point pollution source such as livestock farms have led to pollution of underground water, and thus even the underground water is not safe to be the source of water intake [1].

The small-scale water supply facilities particularly have the operational problems. $19.5 \%$ of Korea small-scale water

Manuscript received May 23, 2016; revised September 2, 2016. This subject is supported by Korea Ministry of Environment (MOE) as "Algae monitoring and removed to utilized R\&D substantiation Project" (2015001800002).

The authors are with the Korea Institute of Civil Engineering and Building Technology(KICT), 283, Goyangdae-Ro, Ilsanseo-Gu, Goyang-Si, Gyeonggi-Do, 10223, Korea (e-mail: jusuk@kict.re.kr, ykpark@kict.re.kr, pjy237@kict.re.kr,woosik@ kict.re.kr, hjoh@ kict.re.kr). supply facilities do not have the sterilization facility, and thus the operator manually injects the solid chloride tablets. $23.0 \%$ nationwide do not sterilize at all. Moreover, they are operated and managed by the village leaders or residents who do not have qualification, and there is no systematic management [2].

As only $18.3 \%$ of the residents using the regional waterworks facilities sterilize them 1 2 times a month, the development and application of the small-scale water supply system to be efficiently managed are urgently needed [3].

Decentralized approaches to supplying water are already applied in many parts of small-scale water supply facilities. These decentralized solutions cover both quality and quantity problems and include the direct use of alternative water sources, household water treatment systems [4].

This study intended to develop and apply the decentralized system for small-scale water supply facilities to ensure safety of water quality. We named it the decentralized water treatment package system. To further develop the system to check the status of the small-scale water supply facilities and monitor the quality of the supply so that it can activate warning and be controlled remotely, the cases currently ongoing in Korea are analyzed, and the developed system is presented in this study.

\section{Stat AS OF SMALl-SCALE WATER SuPPly FACILITY}

In case of Korea, tap water supply rate is $95.1 \%$. Most of the people are under the water supply through central water supply system. In the area without service of central water supply system, if the facility capacity less than $500 \mathrm{~m}^{3}$ per day, small-scale water supply facilities are installed and operated by the local government [5].

Fig. 1 indicated that the number of small-scale water supply facilities and water supply population over 10 years. As 2015, small-scale water supply facilities are present in about 18,511 sites (water supply population of about 150 million people). It corresponds to about $3 \%$ of the population in Korea. We analyzed that each small-scale water supply facility might able to cover for approximately 100 people.

It was shown in Fig. 2 according to the purification process of small-scale water supply facilities. 3,610 sites (19.5\%) purification process is only disinfection process using solid chlorine tablets. 4,258 sites (23.0\%) nationwide do not sterilize at all. Furthermore, only 118 sites (0.6\%) of small-scale water supply facilities were equipped only with membrane process for treatment of low-turbidity water. Furthermore, as shown in Fig. 3, generally most of facilities have less than $100 \mathrm{~m}^{3}$ per day capacity $(16,830$ sites, $90.7 \%)$ in Korea. 


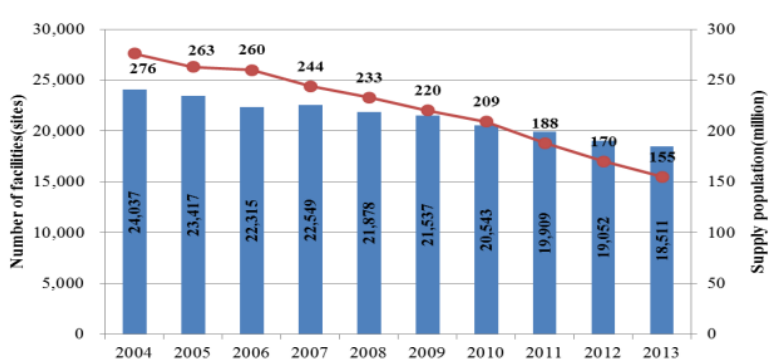

Fig. 1. Number of facilities and supply population over 10 years.

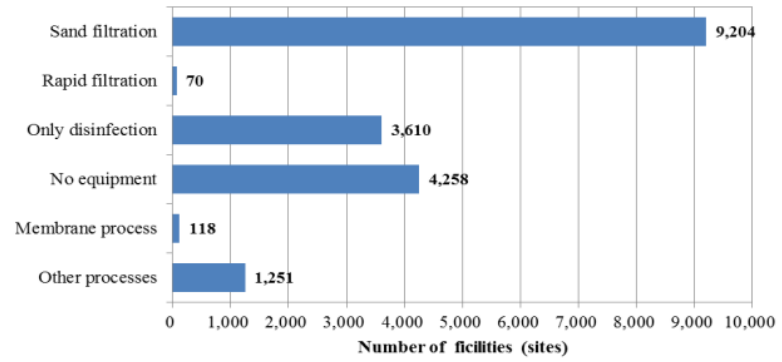

Fig. 2. Number of facilities according to the treatment process.

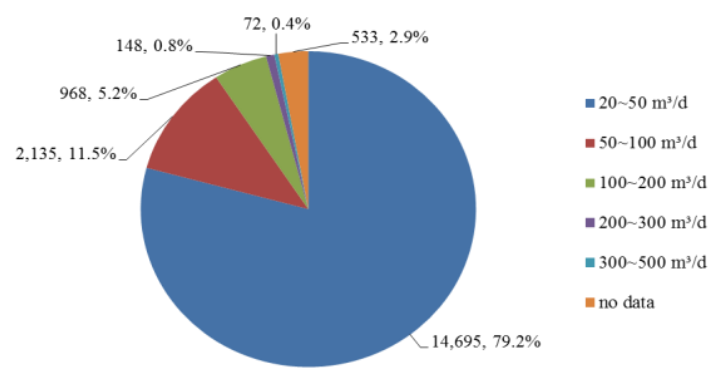

Fig. 3. Number of facilities according to the treatment process.

\section{DECENTRALIZED WATER TREATMENT SySTEM}

The existing water treatment technologies specifically reflect the situation in Korea and thus are limited to be applied as the water treatment system for underground water and valley water. The water treatment system-centric technologies are conservative and passive in that they just respond to simple operation condition changes rather than proactive response to environmental changes. To solve such problems, this study packages each water treatment process specifically for the water quality condition and purpose in each region so that it can be designed and constructed specifically for the region. The differentiating factors of the developed packages include the standardization to suit the characteristics of the process to optimize the capability of the unit process and coding the combination of unit processes to maximize the treatment efficiency [6].

This study developed a decentralized water treatment system in which the units are connected in the form of module as shown in Fig. 4. The process was designed for $100 \mathrm{~m}^{3} /$ day capacity based on the water usage per person per day (around 335 LPCD (liters per capita per day)) so that it can be used as a small-scale water supply system when water service is interrupted. This capacity is sufficient for about 300 people in normal times [7].

\section{A. Physical Removal Process (Left Module in Fig. 4)}

Most of the underground water is detected heavy metal such as arsenic, iron and manganese. DMF (dual media filter) is used a process for removing heavy metals in the ground water. Several types of media can be used, including granular media of various grain sizes. It may be an attractive option for household treatment because they can be produced on the spot with locally available materials; they are mostly simple, easy to use and potentially long-lived. However, regular cleaning is required to maintain flow rates at acceptable levels, so that some skills and knowledge are required to operate and maintain these filters, unless they are fully automated. We have been applying the DMF process for heavy metal treatment. The process was configured to automatically regular cleaning. As well as, the DMF process was modularized to combining with other modules. It can be support various raw water properties [8], [9].

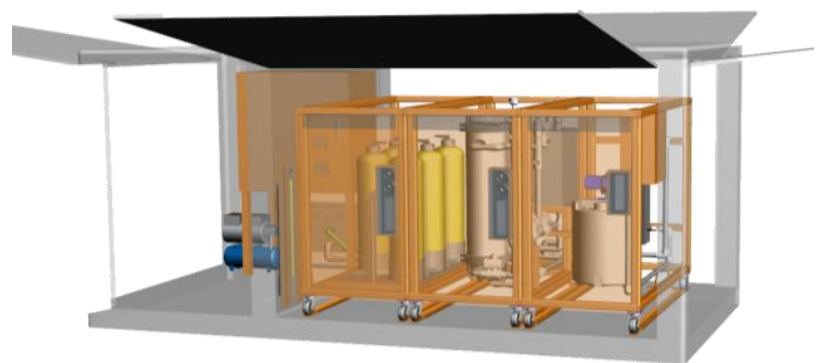

(a) 3D design drawing

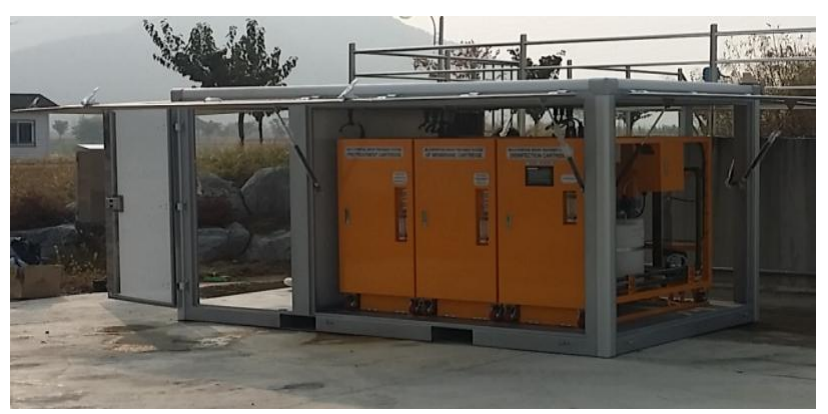

(b) Actual equipmen

Fig. 4. Decentralized water treatment package system.

\section{B. UF (Ultrafilter) Membrane Based Process (Mid Module in Fig. 4)}

Most water-quality problems are due to pathogens, which are completely retained by ultrafiltration membranes. Moreover, UF membranes require significantly lower pressures than RO (Reverse osmosis) membranes, due to the latter's higher resistance and because RO generates an osmotic pressure which counteracts the water transport through the membrane. We have been applying the UF process for treatment of pathogens and low turbidity compounds. The process was configured to automatically operation. And it was also modularized to combining with other modules [10].

\section{UV (Ultraviolet) Disinfection and Auto-control Process (Right Module in Fig. 4)}

In principle, all decentralized technologies can be applied in the same way as the centralized treatment of drinking water. For the smallest scale of systems, some specific technologies and systems have been developed, described and evaluated for household use on the basis of several performance criteria. Besides efficiency in improving the microbiological quality 
of the water and the system costs, these performance criteria include the ease of use of the system or technology.

UV irradiation with lamps has received renewed interest in recent years because of its well-documented ability to extensively $(>99.9 \%)$ inactivate two waterborne, chlorineresistant protozoans, Cryptosporidium parvum oocysts and Giardia lamblia cysts, at relatively low doses. However, UV lamp disinfection has some disadvantages for use as a drinking water disinfectant at household level. Particulates, turbidity and certain dissolved constituents can interfere with or reduce the efficiency of microbial inactivation. But, in our package system, UV disinfection process is a final process of the decentralized water treatment package system, is processed after a physical treatment with a DMF and UF in the front end.

The control unit was designed to not only regulate the whole system automatically but also measure the water quality of the raw water and produced water through a multichannel water quality measurement system. Fig. 4 shows that schematic diagram of treatment process and table 1 shows the detailed measurement range of the multichannel water quality measurement system.
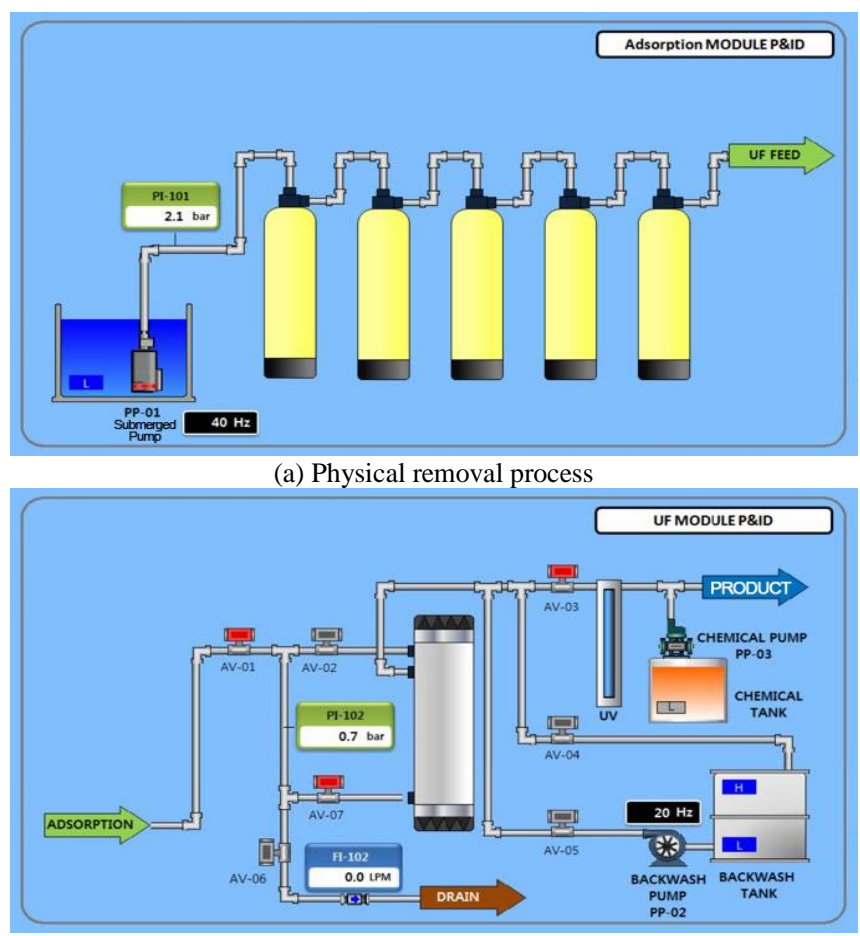

(b) UF membrane based process

Fig. 5. Schematic diagram of decentralized water treatment process.

TABLE I: SPECIFICATION OF MULTICHANNEL WATER QUALITY MEASUREMENT SYSTEM

\begin{tabular}{lccc}
\multicolumn{4}{c}{ MEASUREMENT SYSTEM } \\
\hline \hline Range & Resolution & Accuracy \\
\hline Turbidity & 0 to 1000 & $0.001 \mathrm{NTU}$ & $2 \%$ \\
Temperature & NTU & $0.001{ }^{\circ} \mathrm{C}$ & $0.1^{\circ} \mathrm{C}$ \\
$\mathrm{pH}$ & -5 to $75^{\circ} \mathrm{C}$ & 0.001 & 0.2 \\
Conductivity & $0.01 \sim 100 \mathrm{mS}$ & $0.001 \mathrm{mS}$ & $0.5 \%$ \\
\hline
\end{tabular}

\section{RESUlTS AND DISCUSSION}

This package system was installed and operated at the upper region of the ANDONG small-town in Korea. Fig. 6 indicated that the operating flux and pressure. 8 month operating results $(15.08 \sim 16.03)$, this package system can be operated at a stable flux and pressure and it produced the drinking water of 17,566 tons.

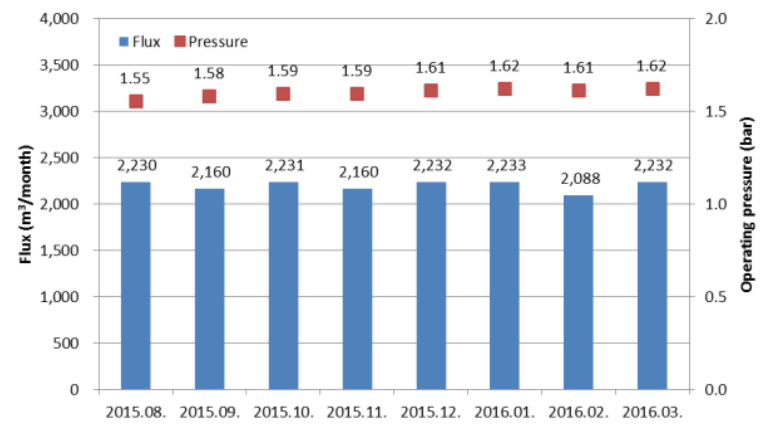

Fig. 6. Decentralized water treatment package system operating flux and pressure.

Fig. 7 shows that results of multichannel water quality measurement system. Turbidity has satisfied the drinking water quality standards in Korea. Furthermore, the electrical conductivity was measured to be lower than the average measured value of Korea tap water.

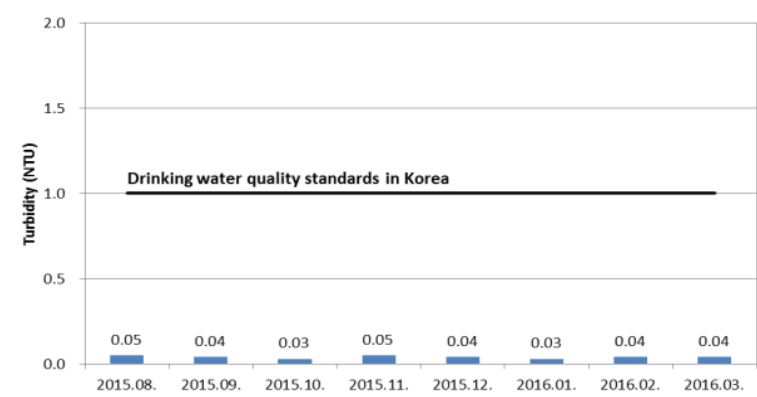

(a) Turbidity

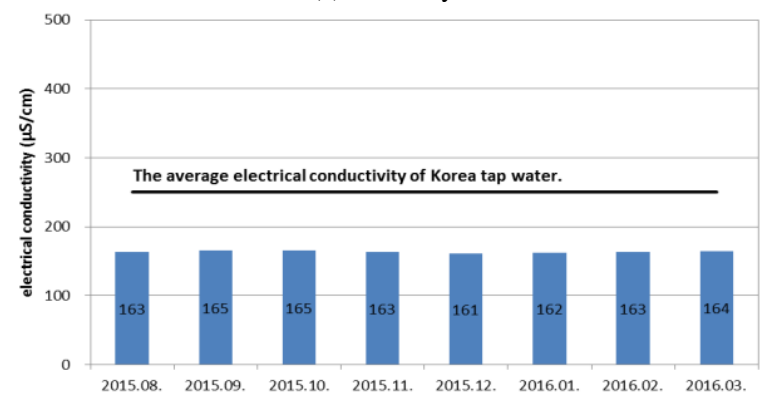

(b) Electrical conductivity

Fig. 7. Measurement data of multichannel water quality measurement system.

\section{CONCLUSION}

South Korea has the characteristic that most of the land is mountainous terrain. Because of its distinctiveness, the dependence of the small-scale water supply facilities is high. From this point of view, that determination of the status of the small-scale water facilities and this provided a suitable water treatment system and effective management plan can be very important. Generally most of small-scale water supply facilities have less than $100 \mathrm{~m}^{3}$ per day capacity (16,830 sites, $90.7 \%$ ) in Korea. Most of facilities are need to water treatment for turbidity and inorganic matter.

Decentralized drinking-water systems are an important element in small-scale water supply facilities. Accordingly, in this study, we developed the membrane based water treatment 
package system for small-scale water supply facility, and its applicability was examined. The decentralized water treatment package system consisted of dual media filter unit (DMF), membrane ultra-filter unit (UF), and ultraviolet unit (UV). Each unit combination was made to ensure the processing capacity of $100 \mathrm{~m}^{3}$ per day.

This package system was installed and operated at the upper region of the ANDONG small-town in Korea. Four items including temperature, $\mathrm{pH}$, conductivity, turbidity were monitored to analyze underground water quality. In addition, the water treated by the decentralized water treatment package system was analyzed to identify whether it satisfies drinking water quality standards. After the examination of applicability, the package system was able to produce enough water for 300 people. During the operation, the produced water satisfied all 48 items of drinking water quality standards Thus it is surmised that the system could be used for small-scale water supply facilities.

\section{ACKNOWLEDGMENT}

This subject is supported by Korea Ministry of Environment (MOE) as "Algae monitoring and removed to utilized R\&D substantiation Project" (2015001800002)

\section{REFERENCES}

[1] R. Cincotta, R. Engelmanm, and D. Anastasion, "The security demographic population and civil conflict after the cold war," Population Action International, Aug. 2003.

[2] ITU, Focus Group on Smart Water Management, 2014.

[3] S. L. Zhou, T. A. McMahonv, A. Walton, and J. Lewis, "Forecasting operational demand for an urban water supply zone," Journal of Hydrology, vol. 259, no. 1-4, pp. 189-202, 2002.

[4] M. Peter-Varbanets, C. Zurbrugg, C. Swartz, and W. Pronk, "Decentralized systems for potable water and the potential of membrane technology," Water Research, vol. 1, no. 43, pp. 245-265, 2009.

[5] The Ministry of Environment, Waterworks Statistics, 2014.

[6] J.-S. An, Y. K. Park, J. Y. Kim, H. J. Oh, and J.-R. Park, "Development of cassette-type water treatment package system for emergencies," International Journal of Engineering and Technology, vol. 7, no. 1, pp 17-20, 2015

[7] EPA, Planning for an Emergency Drinking Water Supply, 2011.

[8] J. K. Park, R. H. Kim, J. Y. Lee, D. H. Choi, and T. D. Kim, "Evaluation of status of groundwater quality monitoring network of Korea: Implications for improvement," Journal of Soil and Groundwater Environment, vol. 12, no. 6, pp. 92-99, 2007.

[9] I. S. Kim, J. Y. Lee, and S. I. Choi, "A study on the characteristic of the groundwater quality in Seoul," Journal of Soil and Groundwater Environment, vol. 9, no. 2, pp. 54-63, 2004.
[10] Y. K. Park, J.-S. An, J. Y. Kim, and H. J. Oh,, "Development of mobile water treatment package system for emergency water supply," International Journal of Civil Engineering Research, vol. 4, no. 3, pp. 296-300, 2015.

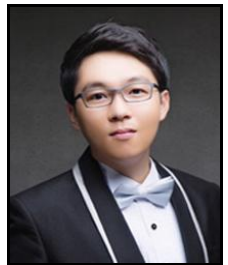

Ju-Suk An received his B.S. in environmenta engineering from Yonsei University, Seoul, Korea in 2010. He received his M.S. in environmental engineering from Yonsei University, Seoul, Korea in 2012. Now, he is present a researcher in Korea Institute of Civil engineering and building Technology (KICT), 283, Goyangdae-Ro, Ilsanseo-Gu, Goyang-Si, Gyeonggi-Do, 411-712, Korea.

Ju Suk An is a researcher at Korea Institute of Civil engineering and building Technology (KICT), Korea. He was born on August 20, 1985, in Inchon, Korea. His early research focused on water chemistry and water treatment process using membrane; his current interests and research is multi-purpose small-scale water treatment package system with the support of the Korean Ministry of Environment as a part of "Global Top Technology Development Project".

Young Kyu Park was born on August 28, 1980 in Daegu, Korea. He raised in Masan, Pusan, Daejeon. He received the B.S. degree (civil \& environmental engineering) in 2009, the M.S. degree (environmental engineering) from Woosong University, in Daejeon, Korea, in 2011.

He has worked as a researcher at Environmental and Plant Engineering Research Institute Korea Institute of Civil Engineering and Building Technology (KICT) from 2011. He has developed multi-purpose small-scale water treatment package system with the support of the Korean Ministry of Environment as a part of "Global Top Technology Development Project".

Jiyoung Park was born on July 28, 1986 in Daejeon, Korea. She received the B.S. degree in environmental engineering in 2009, the M.S. Degree in environmental engineering from University of Science and Technology, in Daejeon, Korea, in 2013.

She has worked as researcher at Environmental and Plant Engineering Research Institute Division in Korea Institute of Civil Engineering and Building Technology from 2014. She has developed multi-purpose small-scale water treatment package system with the support of the Korean Ministry of Environment as part of "Global Top Technology Development Project".

Hyun Je Oh received the B.S. in civil engineering from Yonsei University in 1984 and the M.S. in environmental engineering from Yonsei University in 1986. He then received the Ph.D. from Yonsei University with research in water supply and wastewater (dissertation: Optimization of ozone/AOP, activated carbon and membrane filtering process using ground factor of raw water quality properties) in 2012. Currently, he is a senior research fellow at Environmental Plant Research Center at KICT has been carrying out numerous researches. The projects include "Construction and Environmental Assessment on Site of Large Capacity Pilot Plant for MD/PRO Compound Desalination" Waterworks Research Institutes Conference, Water Management Policy Study Group at the National Assembly, and Deliberation Committee at Korea Environment Corporation. He is currently serving as the Vice Chairman of Korean Society of Water and Wastewater and Seoul Construction Technology Deliberation Committee. 